\title{
Isolation and characterization of new
} microsatellite markers in red tail prawn, Fenneropenaeus penicillatus, an endangered species in China

\author{
Y. Yuan ${ }^{1,2}$, J.B. Shangguan ${ }^{1,2}$, Z.B. Li ${ }^{1,2}$, Y.F. Ning ${ }^{1,2}$, Y.S. Huang ${ }^{1,2}$, \\ B.B. $\mathrm{Li}^{1,2}$ and X.Q. Mao ${ }^{1,2}$ \\ ${ }^{1}$ Fisheries College, Jimei University, Xiamen, China \\ ${ }^{2}$ Fujian Provincial Key Laboratory of Marine Fishery Resources and \\ Eco-Environment, Xiamen, China \\ Corresponding author: Z.B. Li \\ E-mail: lizhongbao@jmu.edu.cn
}

Genet. Mol. Res. 14 (4): 15412-15416 (2015)

Received June 11, 2015

Accepted September 14, 2015

Published November 30, 2015

DOI http://dx.doi.org/10.4238/2015.November.30.18

\begin{abstract}
Until recently, Fenneropenaeus penicillatus was considered a commercial shrimp species. However, in 2005, it was included on the Red List as an endangered species by the Chinese government. In this study, 19 new microsatellite markers in F. penicillatus were developed and tested in samples of 32 wild individuals from Nanao, China. Twelve loci were polymorphic and 7 were monomorphic. Of the 12 polymorphic loci, the number of alleles per locus ranged from 3 to 6 , with an average of 4.42 alleles per locus. The polymorphism information content ranged from 0.302 to 0.670 , with a mean of 0.4817 . The observed and expected heterozygosities ranged from 0.2250 to 0.8889 and from 0.1111 to 0.7750 , respectively. Significant deviations from Hardy-Weinberg equilibrium (HWE, adjusted $\mathrm{P}<0.0042$ ) after a Bonferroni correction were observed in 3 loci (NA-9, NA-57, and NA-64), whereas the other 9 loci were in HWE.
\end{abstract}


These new microsatellite markers will be useful in further research on the population genetic structure of $F$. penicillatus.

Key words: Fenneropenaeus penicillatus; Microsatellite markers; FIASCO protocol

\section{INTRODUCTION}

The red tail prawn (Fenneropenaeus penicillatus) is mainly distributed from Pakistan to Indonesia in the Indo-West Pacific, and it was considered to be one of the most important commercial marine shrimps in the East and South China Seas in the 1980s and 1990s (Zhang et al., 2010; Cao et al., 2012). Because of the prosperity of the fishery industry and loss of habitat, the population of $F$. penicillatus was reduced in some regions. In $2005, F$. penicillatus was included on the Red List as an endangered species by the Chinese government (Wang and Xie, 2009). As the red tail prawn was an important economical shrimp in the past, some effort must be made to revitalize the shrimp industry and to slow down the shrinking of its gene pool.

Microsatellites (also known as simple sequence repeats or SSRs) are short tandem nucleotide repeats located in nuclear DNA, which are inherited co-dominantly in a Mendelian fashion and have high polymorphism. In contrast with single nucleotide polymorphisms (SNP) and genotyping-by-sequencing methods, microsatellite markers are useful in analyzing samples with low DNA quality or concentration. They can be used to assess genetic variability and inbreeding, parentage assignment, species and strain identification, hybridization, and marker-assisted identification of quantitative trait loci through the construction of genetic linkage maps (Liu and Cordes, 2004; Dawson et al., 2013). Microsatellite markers are widely used in the study of wild and cultured aquatic species such as Sebastiscus marmoratus (Li et al., 2013), Branchiostoma belcheri Gray (Dai et al., 2013), and Siganus fuscescens (Ning et al., 2015). Eighteen polymorphic microsatellite loci of $F$. penicillatus have been developed for genetic conservation (Cao et al., 2012; Shangguan et al., 2014). However, they were not sufficient for further study; therefore, 19 additional polymorphic microsatellite loci in F. penicillatus were developed.

\section{MATERIAL AND METHODS}

According to the FIASCO protocol (Zane et al., 2002), we developed new microsatellite markers. Using a modified cetyltrimethylammonium bromide extraction method, genomic DNA was extracted from the tail muscle of five wild $F$. penicillatus individuals, which were captured in Nanao, China. After the DNA concentration was determined, the genomic DNA was diluted to $100 \mathrm{ng} / \mu \mathrm{L}$ with distilled water and stored at $-20^{\circ} \mathrm{C}$.

The restriction enzyme MseI (Fermentas, Vilnius, Lithuania) was used to digest genomic DNA at $65^{\circ} \mathrm{C}$ for $180 \mathrm{~min}$, and the samples were denatured at $80^{\circ} \mathrm{C}$ for $20 \mathrm{~min}$ in a $25-\mu \mathrm{L}$ volume. The fragment digested was tested on $1 \%$ agarose gels. To generate a DNA template for use in subsequent reactions, the fragments digested were ligated to an $M s e I$ adapter 1 (5'-ACGATGAGTCCTGAG-3')/MseI adapter 2 (5'-TACTCAGGACTCAT-3') using T4 DNA ligase (Fermentas) at $22^{\circ} \mathrm{C}$ for $10 \mathrm{~h}$. After denaturation at $95^{\circ} \mathrm{C}$ for $10 \mathrm{~min}$, the fragments were hybridized to the biotinylated oligonucleotide probes $(\mathrm{CT})_{15}$ 
and $(\mathrm{GT})_{15}$ at $61^{\circ} \mathrm{C}$ for $1 \mathrm{~h}$. We used streptavidin-coated magnetic sphere particles (Promega, Madison, WI, USA) to isolate SSRs in the fragments, and the loose DNA fragments were removed by washing. The recovered DNA fragments were amplified by PCR using MseI adapter1. Subsequently, we used GenCleanPCR (Generay, Shanghai, China) to remove the extra adapters and dNTPs for purification. The purified products $(8 \mu \mathrm{L})$ were ligated to $2 \mu \mathrm{L}$ PMD19-T vector (Takara, Shiga, Japan) at $16^{\circ} \mathrm{C}$ for $10 \mathrm{~h}$ in a $10-\mu \mathrm{L}$ volume. Subsequently, the products were transformed into $100 \mu \mathrm{L}$ competent cells of Escherichia coli (Invitrogen, Carlsbad, CA, USA) for further selection on ampicillin plates $(60 \mu \mathrm{g} /$ $\mathrm{mL}$ ). Positive clones were then cultured on 96 -well plates at $37^{\circ} \mathrm{C}$ for $4.5 \mathrm{~h}$ in the presence of ampicillin $(60 \mu \mathrm{g} / \mathrm{mL})$. PCR amplification was conducted to screen the colonies with the use of an M13 primer. After the PCR products were visualized on 1\% agarose gels, 248 clones ranging between 400-1200 bp in size were sequenced by Life Technologies (Guangzhou, China).

In all, 242 fragments were successfully sequenced, and 217 positive colonies contained microsatellite loci after a test using the SSRHunter (version 1.3) software. Seventy one pairs of microsatellite amplification primers were designed by using Primer Premier 5.0.32 (Clarke and Gorley, 2001). After optimizing the amplification conditions for each primer pair in a Mastercycler ${ }^{\circledR}$ Gradient System (Eppendorf, Hamburg, Germany), 33 primer pairs were successfully selected for testing by amplifying the genomic DNA of 32 wild individuals captured in Nanao, China. The PCR amplification was conducted as follows: pre-denaturation at $95^{\circ} \mathrm{C}$ for $5 \mathrm{~min}$, followed by 35 cycles of denaturation at $95^{\circ} \mathrm{C}$ for $30 \mathrm{~s}$, annealing at the optimal temperature (Table 1 ), and $72^{\circ} \mathrm{C}$ for $40 \mathrm{~s}$, with a 10 min elongation at $72^{\circ} \mathrm{C}$. The amplified products were electrophoresed on $6 \%$ denaturing polyacrylamide gels in a Sequi-Gen ${ }^{\circledR}$ Sequencing Cell (Bio-Rad, Hercules, CA, USA), and they were visualized by silver staining. Finally, the number of alleles per locus, the observed and expected heterozygosities, tests for linkage disequilibrium, and Hardy-Weinberg equilibrium (HWE) were calculated by using the POPGEN32 (version 1.32) software (Yeh et al., 2000). Polymorphic information content (PIC) was calculated by using the CERVUS (version 3.0) software.

\section{RESULTS AND DISCUSSION}

Twelve polymorphic and 7 monomorphic microsatellite markers were screened and characterized (Table 1). The remaining markers were excluded because of the Wahlund effect, inbreeding, insufficient amplification, or the presence of non-specific repeated bands. Of the 12 polymorphic microsatellite markers, the number of alleles per locus ranged from 3 to 6 , with an average of 4.42 alleles per locus. The PIC ranged from 0.302 to 0.670 with a mean of 0.4817 . The observed and expected heterozygosities ranged from 0.2250 to 0.8889 and from 0.1111 to 0.7750 , respectively. Significant deviations from HWE (adjusted $\mathrm{P}<0.0042$ ) after a Bonferroni correction were observed at 3 loci (NA-9, NA-57, and NA-64), while the other 9 loci were in HWE. Microsatellites have the highest cross-species utility of all the markers used for genotyping (Dawson et al., 2013), which has been shown in Fenneropenaeus chinensis (Wang et al., 2005) and Capsicum Species (Ince et al., 2010). We believe that the 19 new microsatellite markers will be useful in further research on F. penicillatus and related species. 


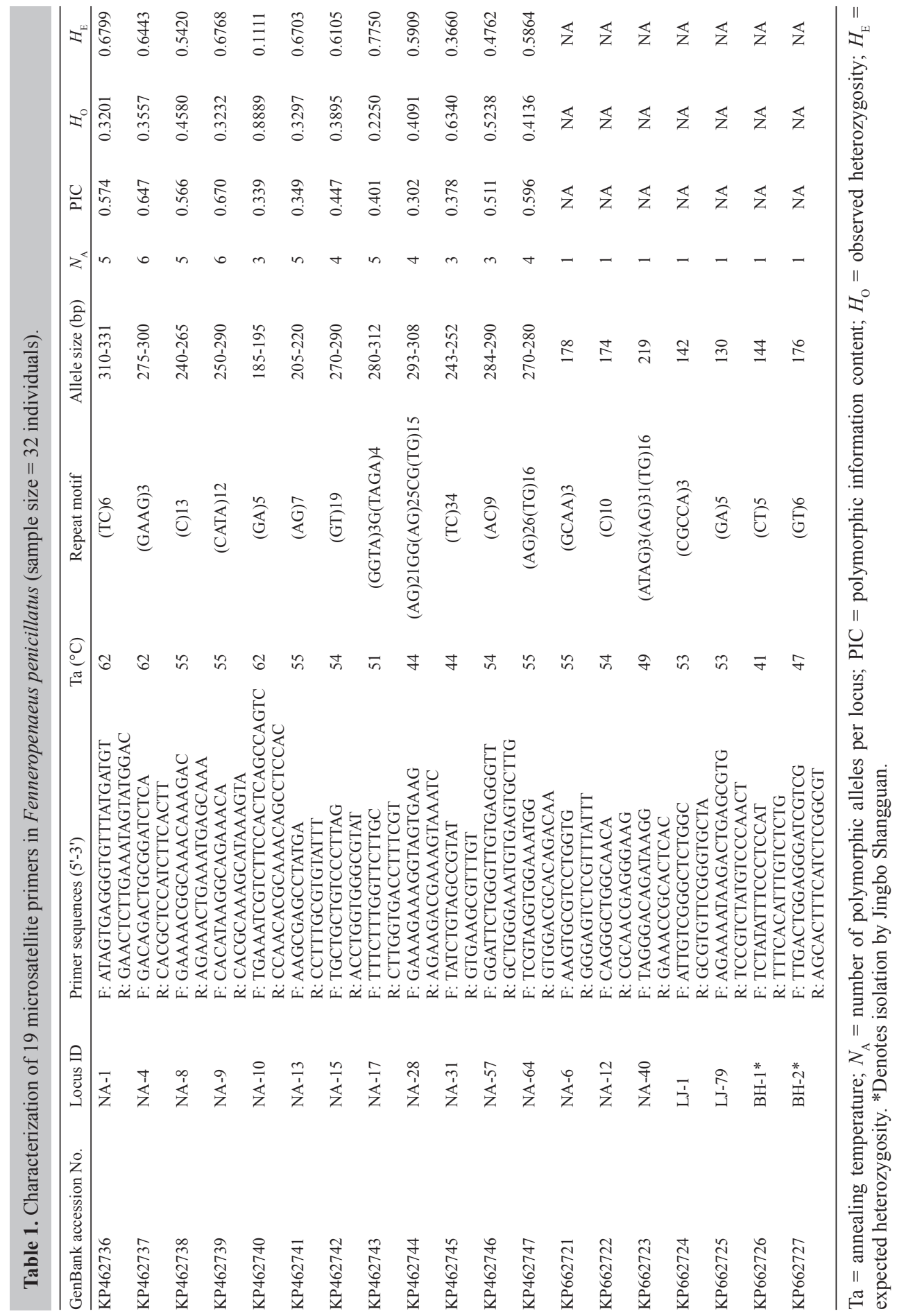




\section{ACKNOWLEDGMENTS}

Research supported by the National Natural Science Foundation of China (\# 31272668), the Natural Science Foundation of Fujian Province (\#2010J01213), the Program of Fujian Provincial Department of Science and Technology (\#JK2010034), the Program for New Century Excellent Talents in Fujian Province University, and the Foundation for Innovative Research Team of Jimei University, China (\#2010A004).

\section{REFERENCES}

Cao YY, Li ZB, Zhang GL, Chen XJ, et al. (2012). Isolation and characterization of ten microsatellite markers of Fenneropenaeus penicillatus. Conserv. Genet. Resour. 4: 261-263.

Clarke KR and Gorley RN (2001). Primer Version 5. Primer-E, Plymouth.

Dai G, Li YY, Li ZB, Li QH, et al. (2013). Isolation and characterization of twelve novel polymorphic microsatellite loci in the Branchiostoma belcheri Gray (Amphioxus). Conserv. Genet. Resour. 5: 1115-1116.

Dawson DA, Alexander DB, Lewis GS, Martín-Gálvez D, et al. (2013). High-utility conserved avian microsatellite markers enable parentage and population studies across a wide range of species. BMC Genomics 14: 1-22.

Ince AG, Karaca M and Onus AN (2010). Polymorphic microsatellite markers transferable across Capsicum species. Plant Mol. Biol. Rep. 28: 285-291.

Li QH, Li ZB, Dai G, Cao Y, et al. (2013). Isolation and characterization of eleven microsatellite loci in the marbled rockfish, Sebastiscus marmoratus (Scorpaenidae). Conserv. Genet. Resour. 6: 53-55.

Liu ZJ and Cordes JF (2004). DNA marker technologies and their applications in aquaculture genetics. Aquaculture 238: $1-37$.

Ning YF, Li ZB, Li QH, Dai G, et al. (2015). Isolation and characterization of novel microsatellite markers for molecular genetic diversity in Siganus fuscescens. Genet. Mol. Res. 14: 89-92.

Shangguan JB, Li ZB, Li QH, Dai G, et al. (2014). Screening and characterization of new microsatellite markers in Fenneropenaeus penicillatus. Genet. Mol. Res. 13: 6079-6082.

Wang S and Xie Y (2009). China Species Red List. 1st Vol. China Higher Education Press, Beijing, China.

Wang HX, Li FH and Xiang JH (2005). Polymorphic EST-SSR markers and their mode of inheritance in Fenneropenaeus chinensis. Aquaculture 249: 107-114.

Yeh FC, Yang R, Boyle TJ, Ye Z, et al. (2000). PopGene 32, Microsoft Windows-based freeware for population genetic analysis, Version 1.32. Molecular Biology and Biotechnology Centre, University of Alberta, Edmonton, Canada.

Zane L, Bargelloni L and Patarnello T (2002). Strategies for microsatellite isolation: a review. Mol. Ecol. 11: 1-16.

Zhang GL, Li ZB, Wang ZL, Lin XY, et al. (2010). Study status and perspective of Fenneropenaeus penicillatus. Mod. Fish. Inform. 2010: 7-10. 